\title{
PERANCANGAN KARAKTER PURNAWARMAN SEBAGAI TOKOH UTAMA DALAM FILM ANIMASI KERAJAAN TARUMANAGARA
}

\author{
Ahmad Surachmad, Iis Purnengsih \\ Program Studi Desain Komunikasi Visual, \\ Fakultas Bahasa dan Seni, Universitas Indraprasta PGRI, \\ Jl. Nangka No. 58 C, Tanjung Barat, Jakarta 12530, Indonesia, \\ surachmad2007@gmail.com,iispurningsih@gmail.com
}

\begin{abstract}
Abstrak
Purnawarman adalah raja ketiga dari Kerajaan Tarumanagara, sosok raja yang gagah berani dalam pertempuran dan raja yang dapat memakmurkan rakyatnya. Sosok yang menarik untuk dijadikan sebuah tokoh utama dalam sebuah cerita sejarah. Artikel ini akan membahas perancangan visual karakter Raja Purnawarman dalam film animasi "Kerajaan Tarumanagara" dengan tujuan untuk mengetahui karakter visual Purnawarman sebagai sosok raja yang gagah berani dalam pertempuran. Analisis visual artikel ini menggunakan analisis Kualitiatif, sehingga dengan analisis ini dapat diketahui karakter Raja Purnawarman. Film animasi dibuat sebagai media pendukung agar karakter visual Purnawarman lebih menarik perhatian khususnya audiens yaitu anak-anak dan remaja.
\end{abstract}

Kata Kunci. Purnawarman, Tarumanagara, Karakter, Animasi.

\begin{abstract}
Purnawarman is the third king of the Tarumanagara Kingdom, he is very brave in the wars and he can also prosperous his nation. He is an interesting figure who able to a main figure in a animation film's story. This article will describe about visual character design of Purnawarman as the king an animation film "Tarumanagara Kingdom", the purposes this article is to know about visual character from the Purnawarman as a brave king in the wars. This article use the qualitative analysis to give the information of The King Purnawarman. This article also use animation film as media to support visual character of The King Purnawarman more interest to attention for the audiences, especially fo the child's and teenagers.
\end{abstract}

Keywords. Purnawarman, Tarumanagara, Charcter, Animation

\section{PENDAHULUAN}

Film animasi merupakan salah satu industri kreatif yang sudah lama berkembang di Indonesia, tetapi dahulu film animasi banyak didominasi oleh animasi - animasi dari luar negeri, salah satunya adalah dari Jepang, seperti film animasi Dragon Ball, Sinchan, Naruto dan lain sebagainya yang rata-rata memiliki penonton dikalangan anak kecil hingga remaja. Saat ini insan muda kreatif di Indonesia mulai membuat karya film animasi yang memiliki kualitas baik dan layak untuk ditayangkan ditelevisi maupun bioskop. Seperti contohnya film animasi dua dimensi berjudul "Battle of Surabaya", yang mengisahkan tentang sejarah pertempuran Surabaya atau pertempuran 10 November. 
Selain sejarah pertempuran Surabaya atau pertempuran 10 November, sebetulnya masih banyak sekali sejarah Indonesia yang harus diketahui dan dipahami oleh anak-anak hingga remaja, karena Indonesia terlahir dari beragam sejarah kerajaan-kerajaannya. Salah satu kerajaan di Indonesia yang menjadi bagian dari sejarah nusantara adalah Kerajaan Tarumanagara. Kerajaan Tarumanagara termasuk kedalam kerajaan tertua di Nusantara yang terdapat di pulau Jawa, merupakan kerajaan dengan kepercayaan Hindu beraliran Wisnu yang mengalami masa kejayaannya pada masa pemerintahan Raja Purnawarman. Para ilmuan berpendapat bahwa kerajaan Tarumanagara berdiri sejak abad ke-4 masehi dan berkembang hingga abad ke-7 masehi. Dalam naskah Wangsakerta dijelaskan bahwa kerajaan Tarumanagara didirikan oleh Rajadirajaguru Jayasingawarman pada tahun 358 masehi. Naskah Wangsakerta adalah naskah yang disusun oleh Pangeran Wangsakerta di Cirebon yang berisi tentang sejarah Sunda dan Nusantara.

Dari cerita sejarah Kerajaan Tarumanagara tersebut, penulis tertarik untuk membuat film animasi Kerajaan Tarumanagara dengan Raja Purnawarman sebagai tokoh utama dalam film tersebut. Dengan tujuan, melalui media film animasi pesan dan cerita yang disampaikan dapat lebih mudah diterima oleh generasi muda khususnya anak-anak dan remaja. Dan perlu kiranya merancang sebuah tokoh utama yang memiliki sifat dan moral yang dapat ditiru oleh penontonya. Secara tidak langsung film tersebut dapat menyampaikan dua hal sekaligus yaitu kreativitas dan edukasi. Kreativitas yang dimaksud adalah bentuk media berupa animasi, dan edukasi terdapat dalam jalan cerita yang merupakan sejarah dari Indonesia.

\section{METODE PENELITIAN}

Metode penelitian yang dipilih menggunakan Metode Kualitatif dengan teknik analisis studi literatur/kepustakaan, observasi dan wawancara, khususunya tentang penciptaan karakter visual melalui elemen-elemen visual dan ciri visual. Hal itu bertujuan agar peneliti mendapatkan data primer dan sekunder, data primer yang dimaksud adalah data utama mengenai berupa visualisasi Purnawarman yang sudah ada sebagai referensi dalam perancangan tokoh, hal itu dapat dilakukan dengan observasi dan studi literatur. Sedangkan untuk data sekunder berupa sifat dan kepribadian Purnawarman dapat diperoleh juga dari studi literatur/kepustakaan dan wawancara. Selanjutnya untuk mendukung data yang ada, perlu dilakukan survey terhadap audiens yang dalam hal ini adalah anak-anak dan remaja dengan cara memilih tokoh dari beberapa pilihan yang ditawarkan yang menurut mereka sesuai dengan sifat dan karakter dari Purnawarman, agar tokoh yang diciptakan sesuai dengan target dan segmentasinya.

\section{HASIL DAN PEMBAHASAN}

Peneliti menggunakan beberapa landasan teori sebagai dasar dalam teknik perancangan karakter Purnawarman, diantaranya :

\section{Semiotika Visual}

Sebuah tanda atau representamen (representamen), menurut Charles S. Pierce (dalam Budiman, 2011:17) adalah sesuatu yang bagi seseorang mewakili sesuatu yang lain dalam beberapa hal atau kapasitas. Sesuatu yang lain itu-dinamakan sebagai interpretan (interpretant) dari tanda yang pertama-pada gilirannya mengacu kepada objek (object). Apabila digambarkan akan membentuk skema sebagai berikut.

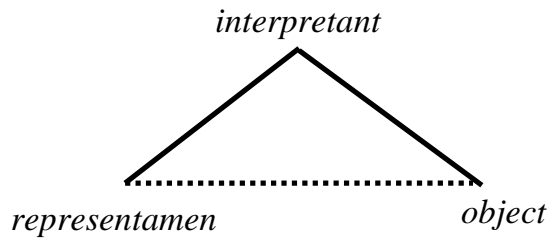


Semiotika visual (visual semiotics) pada dasarnya merupakan salah sebuah bidang studi semiotika yang secara khusus menaruh minat pada penyelidikan terhadap segala jenis makna yang disampaikan melalui sarana indra lihatan (visual senses). (Budiman, 2011:9).

Teori tersebut dapat digunakan pada perancangan ini karena memiliki bahasan terhadap penyelidikan terhadap segala jenis makna yang disampaikan melalui sarana indra penglihatan, segala macam visualisasi yang dilihat oleh manusia akan diproses oleh otak, dan setiap orang akan memiliki persepsi masing-masing, dalam hal ini peneliti harus bisa merancang sebuah tokoh Purnawarman yang sesuai dengan data yang ada sehingga akan tercipta interpretasi (interpretant) dari representasi (representamen) dan objek (object) yang ada.

Dikatakan oleh Barker (dalam Pratama, dkk, 2017) research on culture can be paralleled by the exploration of the process of representation. In other words, the creation of a visual character that refers to the culture of society is a representation of the cultural values inherent in society, yang berarti penelitian tentang budaya dapat disejajarkan dengan eksplorasi proses representasi. Dengan kata lain, penciptaan karakter visual yang mengacu pada budaya masyarakat adalah representasi dari nilai-nilai budaya melekat dalam masyarakat.

Desain karakter dapat dibuat melalui desain garis elemen, yang memvisualisasikan bentuk melalui tipe, ketebalan, orientasi, dan posisi, untuk menghadirkan kepribadian, ekspresi, identitas, dan emosi, gender, kelas sosial. Kemudian unsur-unsur bentuk untuk lebih memperkuat hubungan garis, dan dapat menyajikan penampilan karakter, tipe karakter, dan kepribadian. (Pratama, dkk, 2017)

Dari teori dan ciri objek yang ada, peneliti dapat mengambil sebuah kesimpulan dari hubungan dan korelasi yang ada. Sehingga penelitian ini dapat membuat perancangan sebuah karakter, sesuai dengan pendapat Kurniawan (dalam Wahyuningsih, 2014) semiotika (atau semiologi) Roland Barthes mengacu kepada Saussure dengan menyelidiki hubungan antara penanda dan petanda pada sebuah tanda. Hubungan penanda dan petanda ini bukanlah kesamaan (equality), tetapi ekuivalen. Bukannya yang satu kemudian membawa pada yang lain, tetapi korelasilah yang menyatukan keduanya.

\section{Gaya Visual}

Gaya visual perancangan tokoh Purnawarman dalam hal ini peneliti menggunakan gaya kartun, menurut Waluyanto (dalam Putri, 2013) keunggulan dari media film kartun yaitu: a) lebih mudah diingat penggambaran karakter yang unik; b) efektif langsung pada sasaran yang dituju; c) efisien sehingga memungkinkan frekuensi yang tinggi; d) lebih fleksibel mewujudkan hal-hal khayal; e) dapat diproduksi setiap waktu; f) dapat dikombinasikan dengan live action; g) kaya akan ekspresi warna.

Selain itu mengacu kepada target film animasi Kerajaan Tarumanagara yaitu anak kecil hingga remaja, maka gaya kartun dianggap tepat dengan sasarannya.

\section{Tinjauan Objek}

Dua tahun sebelum ayahnya (Rajaresi Darmayawarman-guru) wafat, ia (Purnawarman) diwisuda sebagai raja Tarumanagara ketiga, pada tanggal 13 bagian terang bulan Caitra tahun 317 saka (12 Maret 395 Masehi).

Purnawarman merupakan raja yang gagah berani, hal tersebut tertulis dalam Prasasti Ciaruteun yaitu salah satu prasasti peninggalan Kerajaan Tarumanagara. Prasasti tersebut kirakira berbunyi sebagai berikut : Ini [bekas] dua kaki, seperti kaki dewa Wisnu, ialah kaki yang mulia Sang Purnawarman, raja di negeri Taruma, raja yang gagah berani di dunia (Munandar, 2017:75).

Dalam Prasasti Jambu yang ditemukan di Bukit Pasir Koleangkak memuat petunjuk dan keterangan yang penting mengenai Raja Purnawarman. Bahwa Raja Purnawarman memakai warman atau baju zirah, yaitu baju rantai atau baju besi. Disebutkan pula bahwa warman atau baju zirah baginda terkenal tidak dapat ditembus oleh senjata musuh (Munandar, 2017:78). 
Tidak ada satupun senjata musuh yang dapat melukainya karena dalam perang ia selalu mengenakan baju pelindung dari besi yang dipasangnya mulai dari kepala sampai ke kaki (Iskandar, 2017:63-64).

Secara fisik tubuhnya, Raja Purnawarman memiliki lengan kencang dan kuat, hal tersebut disebutkan dalam Prasasti Tugu yang ditemukan di daerah Cilincing, yang sebagian isinya sebagai berikut : Dulu (kali yang bernama) Kali Candrabhaga telah digali oleh maharaja yang mulia dan mempunyai lengan kencang dan kuat (yakni raja Purnawarman). (Munandar, 2017:77). Untuk mengetahui bagaimana wajah dan rambut Purnawarman, peneliti dapat menarik kesimpulan bahwa fisik wajah Purnawarman masih memiliki kemiripan dengan bangsa India, hal tersebut disimpulkan karena Jayasingawarman yang merupakan kakek dari Purnawarman dan sekaligus pendiri kerajaan Tarumanagara berasal dari India. Berdasarkan naskah Wangsakerta (dalam Iskandar, 2017:60) dikisahkan pada tahun 270 Saka atau tahun 348 masehi, ada seorang maharesi Hindu dari keluarga Calakankayana mengungsi ke pulau-pulau sebelah selatah India. Bersama pengikutnya yang terdiri dari pengiring, tentara dan penduduk pria-wanita melarikan diri karena pihak musuh (Samudrgupta) selalu berusaha menangkap mereka. Sang maharesi yang bernama Jayasingawarman bersama pengikutnya akhirnya tiba di Pulau Jawa.

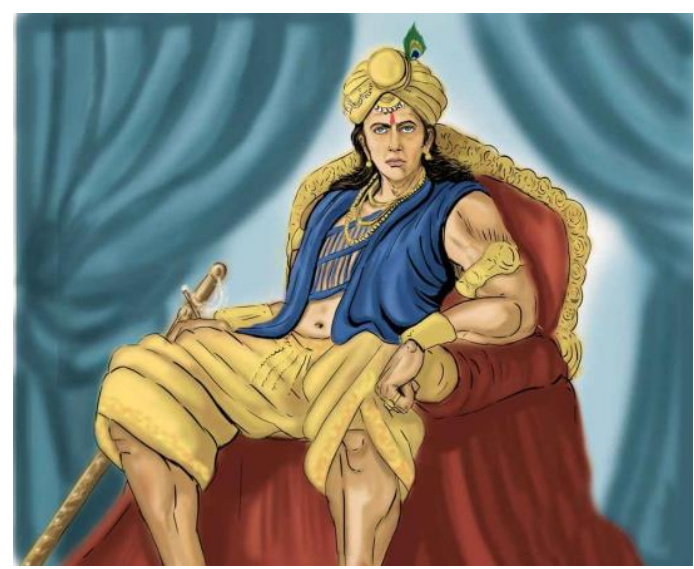

Gambar 1 Visualisasi Raja Kerajaan Samudragupta sebagai data visual raja dari India Sumber : http://hindutav.com/wp-content/uploads/2015/01/chandragupta_maurya_by_mrinal_raid760bch.jpg

Menurut Pustaka Prawatan i Bhumi Jawadwipa (dalam Achmad S.W, 2018:39) bahwa Purnawarman saat menaklukkan raja-raja Salakanagara dan Purwalingga selalu menunggang gajah Airwata, dalam mitologi Hindu, gajah merupakan tunggangan Bhatara Indra. Pustaka tersebut juga menjelaskan, bahwa bendera Kerajaan Tarumanagara berlukiskan rangkaian bunga teratai di atas kepala gajah. Demikian pula mahkota yang dikenakan oleh Purnawarman, memiliki ukiran sepasang lebah.

Emas dan perak kemungkinan menjadi komoditi yang besar dalam Kerajaan Tarumanagara. Kemungkinan akan adanya pertambangan, kita peroleh dari berita tentang diperdagangkannya emas dan perak yang disebutkan sebagai salah satu hasil tambang daerah itu (Poesponegoro, 2009:60).

Kerajaan Tarumanagara yang dilewati oleh sungai Citarum, memliki warna khas yaitu biru. Hal tersebut disimpulkan karena sepanjang sungai Citarum banyak tumbuh tanaman Tarum, atau secara ilmiah disebut Indigofera. Tanaman Tarum digunakan sebagai bahan pewarna kain atau pakaian, karena menghasilkan warna biru.

Dari tinjauan objek tersebut dapat disimpulkan beberapa data sebagai dasar perancangan karakter diantaranya yaitu, Raja Purnawarman merupakan sosok raja gagah berani yang secara fisik memiliki lengan yang kencang dan kuat. Gagah, berani, lengan kencang dan kuat dapat di interpretasikan sebagai sosok yang memiliki badan yang berotot. Untuk pakaian yang digunakan, disebutkan bahwa Purnawarman dalam berperang menggunakan warman atau baju zirah terbuat 
dari besi dan tidak dapat ditembus oleh senjata musuh yang digunakan dari kepala hingga kaki. Dapat disimpulkan bahwa pada saat berperang, Purnawarman menggunakan pakaian perang yang sangat tertutup. Tetapi dalam kesehariannya, peneliti berpendapat bahwa Purnawarman menggunakan pakaian raja yang terbuat dari emas ataupun perak yang dipadukan dengan mahkota yang memiliki ukiran sepasang lebah serta pakaian berbahan kain berwarna biru.

Purnawarman memimpin Kerajaan Tarumanagara selama kurang lebih 39 tahun (395-434 M). Setelah masa kepemimpinan Purnawarman selesai atau setelah Purnawarman wafat, kepemimpinan kerajaan Tarumanagara dilanjutkan oleh Wisnuwarman dan hingga sampai kepemimpinan Linggawarman.

Alasan memilih tokoh Purnawarman karena sebagian besar didalam prasasti peninggalan Kerajaan Tarumanagara menceritakan tentang Puranawarman sebagai raja yang kuat, gagah, berani dan merupakan seorang pemimpin yang peduli terhadap rakyatnya. Sehingga menjadikan sosok Purnawarman menjadi tokoh utama adalah pilihan yang tepat.

\section{Hasil Penelitian}

\begin{tabular}{|l|l|l|}
\hline \multirow{4}{*}{$\begin{array}{l}\text { Karakter } \\
\text { Visual }\end{array}$} & Object & Reprsentamen \\
\cline { 2 - 3 } & $\begin{array}{l}\text { Objek Unsur } \\
\text { Visual }\end{array}$ & Representasi Perancangan \\
\hline \multirow{5}{*}{ Purnawarman } & Badan & Tegap, gagah dan berotot \\
\cline { 2 - 3 } & Wajah & Seperti orang India \\
\cline { 2 - 3 } & Warna Kulit & Coklat, sesuai dengan iklim tropis wilayah pesisir pulau Jawa \\
\cline { 2 - 3 } & Rambut & $\begin{array}{l}\text { Tidak terlalu panjang berwarna hitam } \\
\text { Berkumis (menunjukkan kesan gagah) }\end{array}$ \\
\cline { 2 - 3 } & Hidung & Mancung \\
\cline { 2 - 4 } & Pakaian & $\begin{array}{l}\text { Menggunakan bahan kain berwarna biru, } \\
\text { Terdapat pakaian berbahan emas, besi atau perak } \\
\text { Menggunakan mahkota raja }\end{array}$ \\
\cline { 2 - 4 } & Mahkota & Berbahan dasar emas dan memiliki ukiran sepasang lebah \\
\hline
\end{tabular}

\section{Hasil Perancangan}

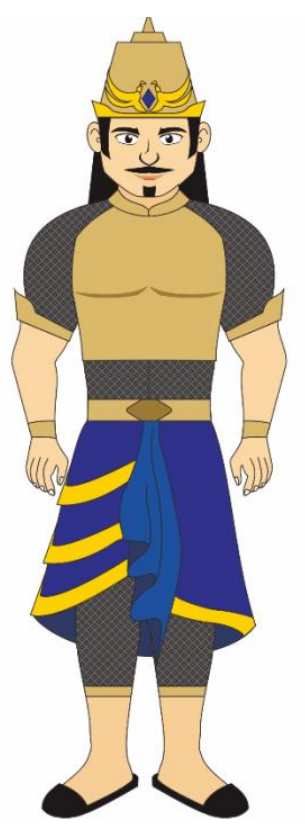

Gambar 2 Hasil akhir perancangan karakter Purnawarman (sisi depan)

Sumber: Ahmad Surachmad 


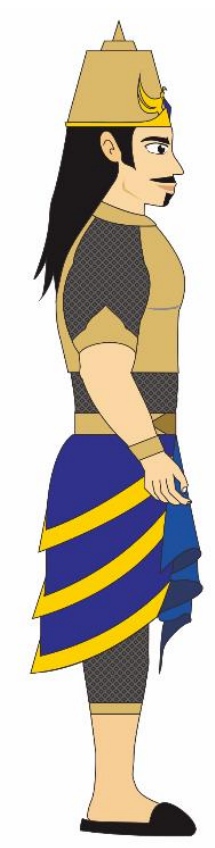

Gambar 3 Hasil akhir perancangan karakter Purnawarman (sisi samping) Sumber: Ahmad Surachmad

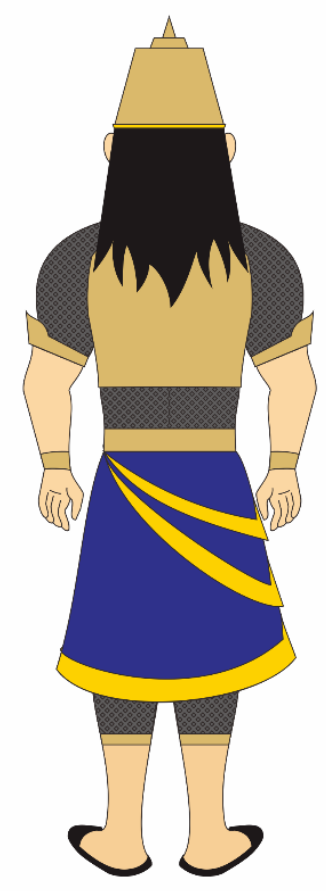

Gambar 4 Hasil akhir perancangan karakter Purnawarman (sisi belakang)

Sumber: Ahmad Surachmad

Sesuai dengan data dan hasil penelitian yang didapat, serta mengacu kepada teori yang ada. Terciptalah sebuah rancangan karakter Purnawarman sebagai tokoh utama dalam film animasi Kerajaan Tarumanagara. Kesan yang tercipta adalah karakter dengan sifat gagah, berani, kuat dan memiliki jiwa pemimpin.

\section{SIMPULAN}


Dari hasil penelitian tersebut terciptalah sebuah karakter tokoh Purnawarman yang didasarkan pada hasil penelitian dan data visual yang ada. Sehingga karakter Purnawarman dalam film animasi Kerajaan Tarumanagara diharapkan dapat menjadi tokoh utama yang memiliki nilainilai budaya Indonesia dan pesan moral bagi anak-anak dan remaja yang menjadi sasaran utama dalam film tersebut.

Selain itu diharapakan karakter Purnawarman dapat menjadi sebuah tokoh yang ditiru dalam hal sifat dan cara kepemimpinannya, sehingga terciptalah jiwa-jiwa pemimpin seperti halnya Purnawarman di kalangan generasi muda.

\section{DAFTAR PUSTAKA}

Achmad, S.W. (2018). Sejarah perang kerajaan-kerajaan di Nusantara. Yogyakarta: Araska Publisher.

Budiman, K. (2011). Semiotika visual:Konsep, isu, dan problem ikonisitas. Yogyakarta: Jalasutra.

Djafar, H. (2010). Kompleks Percandian Batujaya, Rekonstruksi sejarah kebudayaan daerah Pantai Utara Jawa Barat. Bandung: Kiblat Buku Utama.

Iskandar, Y. (2017). Sejarah Jawa Barat (Yuganing Rajakawasa). Bandung: CV Geger Sunten.

Munandar, A.A., (2017). Kaladesa: Aawal sejarah Nusantara. Jakarta: Wedatama Widya Sastra.

Poesponegoro, M.D., \& Notosusanto, N. (2010). Sejarah Nasional Indonesia II: Zaman Kuno. Jakarta: Balai Pustaka.

Pratama, D., Wardani, W. G. W., \& Akbar, T. (2017). Designing visual character of Raden Wijaya as historical figure in visual novel. International Journal Of Scientific \& Technology Research, 6(11), 207-210.

Putri, A., \& Tria, W. (2013). Penggunaan Media Film Kartun Untuk Meningkatkan Keterampilan Menyimak Cerita Di Sekolah Dasar. Jurnal Penelitian Pendidikan Guru Sekolah Dasar, $1(2), 1-10$.

Wahyuningsih, S. (2014). Kearifan budaya lokal Madura sebagai media persuasif (analisis semiotika komunikasi Roland Barthes dalam iklan Samsung Galaxy versi Gading dan Giselle di pulau Madura). SOSIO-DIDAKTIKA: Social Science Education Journal, 1(2), 171-180.

Anand. (2015). Samudragupta: Life, Conquests, Administration and Culture. [Gambar]. http://www.historydiscussion.net/biography/samudragupta-life-conquestsadministration-and-culture/3082 